\title{
Microbial community structures in anoxic freshwater lake sediment along a metal contamination gradient
}

\author{
Heidi L Gough and David A Stahl \\ Department of Civil and Environmental Engineering, University of Washington, Seattle, WA, USA
}

\begin{abstract}
Contamination, such as by heavy metals, has frequently been implicated in altering microbial community structure. However, this association has not been extensively studied for anaerobic communities, or in freshwater lake sediments. We investigated microbial community structure in the metal-contaminated anoxic sediments of a eutrophic lake that were impacted over the course of $\mathbf{8 0}$ years by nearby zinc-smelting activities. Microbial community structure was inferred for bacterial, archaeal and eukaryotic populations by evaluating terminal restriction fragment length polymorphism (TRFLP) patterns in near-surface sediments collected in triplicate from five areas of the lake that had differing levels of metal contamination. The majority of the fragments in the bacterial and eukaryotic profiles showed no evidence of variation in association with metal contamination levels, and diversity revealed by these profiles remained consistent even as metal concentrations varied from 3000 to $27000 \mathrm{mg} \mathrm{kg}^{-1}$ total $\mathrm{Zn}, 0.125$ to $11.2 \mu \mathrm{M}$ pore water $\mathrm{Zn}$ and 0.023 to $5.40 \mu \mathrm{M}$ pore water As. Although most archaeal fragments also showed no evidence of variation, the prevalence of a fragment associated with mesophilic Crenarchaeota showed significant positive correlation with total $\mathrm{Zn}$ concentrations. This Crenarchaeota fragment dominated the archaeal TRFLP profiles, representing between $35 \%$ and $79 \%$ of the total measured peak areas. Lake DePue 16S rRNA gene sequences corresponding to this TRFLP fragment clustered with anaerobic and soil mesophilic Crenarchaeota sequences. Although Crenarchaeota have been associated with metal-contaminated groundwater and soils, this is a first report (to our knowledge) documenting potential increased prevalence of Crenarchaeota associated with elevated levels of metal contamination.

The ISME Journal (2011) 5, 543-558; doi:10.1038/ismej.2010.132; published online 2 September 2010

Subject Category: microbial ecosystem impacts

Keywords: aquatic sediment; archaea; crenarchaeota; metal contamination; TRFLP; zinc
\end{abstract}

\section{Introduction}

Established models in macroecology predict that community diversity will decrease in response to stresses associated with toxic compounds (Odum, 1985). This response has been observed for microbial diversity in aerobic soils contaminated by metals (Smit et al., 1997; Bååth et al., 1998b; Sandaa et al., 1999b; Moffett et al., 2003). In addition, some studies suggest that in soil environments changes to microbial community structure can be detected without apparent changes in microbial biomass or activity when communities are exposed to low levels of metal contamination (Frostegård et al., 1996; Bååth et al., 1998a). DiazRavina and Bååth (1996) postulated that microbial community structures in metal impacted environments could change without associated total biomass loss when biomass

Correspondence: HL Gough, Department of Civil and Environmental Engineering, University of Washington, Box 352700, Seattle, WA 98195-2700, USA.

E-mail: hgough@u.washington.edu

Received 19 April 2010; revised 8 July 2010; accepted 11 July 2010; published online 2 September 2010 that was lost by the death of metal-sensitive species was replaced by increased biomass of more resistant species. This hypothesis is supported by large ranges of reported minimum inhibitory concentrations documented for a single metal (for example, compare the results of Mahapatra and Banerjee, 1996; Kunito et al., 1997; Hassen et al., 1998; Utgikar et al., 2001; Hayat et al., 2002). The primary goal of the work described here was to compare microbial community structures in anoxic freshwater sediment samples with differing levels of metal contamination.

Metal contamination of soils and sediments is widespread. These contaminants are associated with a wide range of human activities including mining and smelting (Helmisaari et al., 1995; La Force et al., 1999; Jensen et al., 2000; Aslibekian and Moles, 2003), and land application of sludge and biosolids (Speir et al., 2003). Some contaminated soil sites date back as far as the Bronze age (Prusty et al., 1994; Pyatt et al., 2000). In aquatic systems, sediments are a main depository of metal contaminants.

Because of their critical ecological role in lake ecosystems, metal's impacts on freshwater sediments 
may potentially have system-wide implications. The microbial populations in anoxic lake sediments mediate biogeochemical recycling of carbon, sulfur and phosphorus back to the water column (Ingvorsen et al., 1981; Billen, 1982; Jones, 1982; Holmer and Storkholm, 2001). In particular, the competition between sulfate-reducing bacteria and methanogenic Archaea has long been studied for its important impact to sediment carbon cycling (Winfrey and Zeikus, 1977; Mountfort and Asher, 1981). Despite their ecological importance, studies reporting the impacts of metal contamination on anaerobic sediment communities remain limited. Capone et al. (1983) first reported that metal contaminants experimentally introduced to sediment from a salt marsh could inhibit sulfate reduction while simultaneously stimulating methane generation. Recently, Grandlic et al. (2006) reported that low levels of $\mathrm{Pb}$ contamination in anoxic freshwater sediment may impact the community structure of the culturable fraction of the indigenous microbes. The study presented here expands on these previous studies of anaerobic community response to metals by examining the microbial community structures in anoxic freshwater lake sediments after exposure to more than 80 years of metal contamination.

The study lake (Lake DePue, Illinois, USA) is a naturally eutrophic backwater lake on the Illinois River, which has been impacted by nearby Zn-smelting activities. The lake has previously been characterized, documenting that higher metal contamination levels correlated with lower biomass concentrations (Gough et al., 2008a). Samples collected during this previous field study were further analyzed to profile their resident microbial communities for each of the three domains. A field study was used (rather than a laboratory study with experimentally manipulated metal concentrations) to allow examination of the influence of chronic metals exposure. As this study represents a first examination of the impacts of metal contamination on anaerobic freshwater lake sediment communities, it focused on molecular methods with broad resolution at the biologic domain level-rather than on a specific population or functional group-to allow inclusion of potentially unanticipated microbial populations. Carbon, nitrogen and $\mathrm{pH}$ were also monitored to differentiate potential influence of these parameters from those associated with metal contamination. Similar strategies based on comparison of samples with varying contamination levels have been used by others to monitor changes associated with metal contamination to microbial communities in aerobic soils (Smit et al., 1997; Konopka et al., 1999; Becker et al., 2006). Here, this approach was applied to evaluate anaerobic freshwater lake sediments, in which community structures were found to be highly similar despite drastically differing metal contamination levels. Despite the consistency observed for overall community structure, statistically significant correlations with metal concentrations were found for several microbial populations, including a strong positive correlation between metal contamination levels and a molecular signature identified to be associated with Crenarchaeota.

\section{Materials and methods}

\section{Field site description}

Lake DePue (latitude $41^{\circ} 19^{\prime} \mathrm{N}$, longitude $89^{\circ} 18^{\prime} \mathrm{W}$ ) is a shallow, naturally eutrophic, backwater lake connected by a narrow channel to the Illinois River (Figure 1). This lake is fed by surface runoff that is channeled through the lake to the Illinois River. Water depths in the lake range from 1 to $15 \mathrm{~m}$, and fluctuate with the occurrence of storm events. Metal contamination migrated to the lake sediments from a Zn smelter that operated near the north lakeshore for approximately 80 years (Cahill and Bogner, 2002). This adjacent facility is currently listed on the United States Environmental Protection Agency National Priority List (aka Superfund, Site ID no. ILD062340641). A man-made creek draining into the northeast corner of the lake is a likely migration path for the metals. As a result of naturally high organic loading, sediments within this lake become anoxic within the first 1-2 mm below the sedimentwater interface (data not shown). Thus, this field site allows study of the influence of metal contamination on anaerobic microbial sediment communities following long-term exposure (more than 80 years) over a naturally established contamination concentration gradient (Webb et al., 2000; Gough et al., 2008a, 2008b).

Description of sampling sites and sample collection In September 2000, three replicate cores were collected from each of five sampling sites using a

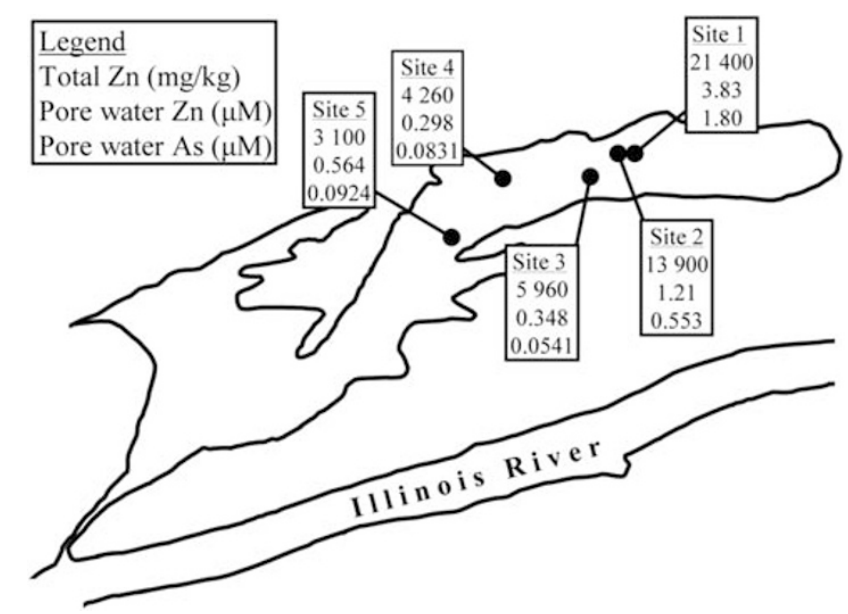

Figure 1 Sampling locations in Lake DePue, Illinois, USA $\left(41^{\circ} 19^{\prime} \mathrm{N}, 89^{\circ} 18^{\prime} \mathrm{W}\right)$ including average metal contamination levels for total $\mathrm{Zn}$, pore water $\mathrm{Zn}$ and pore water As. Summarized from Gough et al. (2008a). 
Table 1 Summary of chemical and physical properties in Lake DePue sediments (September 2000)

\begin{tabular}{|c|c|c|c|}
\hline \multirow[b]{2}{*}{ Environmental variables } & \multirow[t]{2}{*}{ Average } & \multicolumn{2}{|c|}{ Range } \\
\hline & & & \\
\hline $\mathrm{pH}$ & 7.8 & 7.5 & 8.2 \\
\hline Total organic carbon $\left(\mathrm{mg} \mathrm{kg}^{-1}\right)$ & 48100 & 34500 & 62500 \\
\hline Dissolved organic carbon (mM C) & 1.58 & 0.774 & 3.37 \\
\hline Total nitrogen $\left(\mathrm{mg} \mathrm{kg}^{-1}\right)$ & 4230 & 2650 & 5760 \\
\hline \multicolumn{4}{|l|}{ Pore water metal concentrations } \\
\hline Arsenic $(\mu \mathrm{M})$ & 0.516 & 0.0233 & 5.40 \\
\hline Cadmium $(\mu \mathrm{M})$ & 0.00844 & 0.00357 & 0.0454 \\
\hline Chromium $(\mu \mathrm{M})$ & 0.092 & 0.019 & 0.593 \\
\hline Copper $(\mu \mathrm{M})$ & 0.127 & 0.0140 & 1.17 \\
\hline Lead $(\mu \mathrm{M})$ & 0.0101 & 0.00241 & 0.0414 \\
\hline Manganese $(\mu \mathrm{M})$ & 26.7 & 14.3 & 38.2 \\
\hline Zinc $(\mu \mathrm{M})$ & 1.25 & 0.125 & 11.2 \\
\hline \multicolumn{4}{|l|}{ Total metal concentrations } \\
\hline Cadmium $\left(\mathrm{mg} \mathrm{kg}^{-1}\right)$ & 51.1 & 13.6 & 118 \\
\hline Copper $\left(\mathrm{mg} \mathrm{kg}^{-1}\right)$ & 350 & 91.6 & 350 \\
\hline Iron $\left(\mathrm{mg} \mathrm{kg}^{-1}\right)$ & 27800 & 22800 & 34800 \\
\hline Lead $\left(\mathrm{mg} \mathrm{kg}^{-1}\right)$ & 180 & 68.6 & 541 \\
\hline Manganese $\left(\mathrm{mg} \mathrm{kg}^{-1}\right)$ & 833 & 713 & 1250 \\
\hline Zinc $\left(\mathrm{mg} \mathrm{kg}^{-1}\right)$ & 9710 & 3040 & 27000 \\
\hline
\end{tabular}

Data summarized from: Gough et al. (2008a).

hand-held piston core sampler (15 cores total) as part of a comprehensive study on metal speciation and microbial biomass within Lake DePue (Gough et al., 2008a). A summary of the ranges of the observed metal concentrations and environmental variables is shown in Table 1 , and more detailed results can be found in Gough et al. (2008a), including descriptions of the inductively coupled plasma-mass spectrometry and flame atomic absorption spectrometry methods used to quantify the metals. Replicate samples were collected from multiple sites with different levels of metal contamination to allow examination of differences along a metal contamination gradient, while minimizing the influence of temporal changes potentially introduced by sampling over time. In addition to the samples for metals and biomass, sediments were collected and archived for DNA extraction. Immediately after collection, the top $2 \mathrm{~cm}$ of each core was extruded in $1 \mathrm{~cm}$ intervals, homogenized in sterile cups under a nitrogen gas stream, aliquoted into $2 \mathrm{ml}$ screw-top tubes and placed in dry ice for transport (30 individual samples total). In the laboratory, sediment sample aliquots were stored at $-80^{\circ} \mathrm{C}$ until processed for DNA or RNA extraction. Further detailed chemistry and biomass data for the 30 samples are reported elsewhere (Gough et al., 2008a).

\section{DNA extraction}

Sediment samples $(\sim 0.5 \mathrm{ml}$ aliquots $)$ were washed three times with $1 \mathrm{ml}$ of $40 \mathrm{mM}$ sodium ethylenediaminetetraacetate (EDTA) prepared in $100 \mathrm{~mm}$ Tris-HCl (pH 7). Following each wash, samples were centrifuged at $10000 \mathrm{~g}$ at $4{ }^{\circ} \mathrm{C}$, and the supernatant was discarded. The wash was intended to remove excess divalent metals before cell lysis, because high concentrations of divalent cations, such as the $\mathrm{Zn}$ found in the Lake DePue sediments, might contribute to premature precipitation of DNA (Kejnovsky and Kypr, 1997). Extractions from the Lake DePue sediments conducted without this wash step were found to yield either no DNA or poorquality DNA that would not yield to PCR (data not shown). Comparison of terminal restriction fragment length polymorphism (TRFLP) profiles prepared using a control sediment (Parker River Sediments with no known metal contaminants) (1) with the EDTA-Tris wash, (2) with a Tris wash containing no EDTA (100 mM Tris-HCl, pH 7) and (3) with no wash step were highly similar (data not shown), showing that no measurable bias was introduced by the EDTA-Tris washing step.

Following sediment washing, DNA was extracted from the samples using an UltraClean soil DNA isolation kit from MoBio in accordance with the manufacturer's instructions except that bead-beating was conducted for $20 \mathrm{~s}$ at a speed of 4.5 in a Bio101 FastPrep Cell Disruptor (model 120A, BIO101; now MP Biomedical, Solon, OH, USA).

\section{Polymerase chain reaction conditions and primers}

Three primers sets were used, each targeting the small subunit (SSU) rRNA gene of one of the biological domains (Table 2). PCR reaction mixtures and run conditions were optimized for each primer set. PCR mixtures targeting Bacteria consisted of primers (8F and 1492R, $0.2 \mathrm{mM}$ each), $0.02 \mathrm{U}_{\mu \mathrm{l}^{-1}}$ DNA polymerase (Fermentus Taq), $0.2 \mathrm{mM}$ dNTPs (Fermentus), $0.1 \mathrm{mg} \mathrm{ml}^{-1}$ bovine serum albumin and $1.25 \mathrm{mM}$ $\mathrm{MgCl}_{2}$. PCR mixtures targeting Archaea consisted of primers $\left(21 \mathrm{~F}\right.$ and $915 \mathrm{R}, 0.5 \mathrm{mM}$ each), $0.025 \mathrm{U}_{\mu \mathrm{l}^{-1}}$ DNA polymerase (Fermentus Taq), $1 \mathrm{mM}$ dNTPs (Fermentus), $0.125 \mathrm{mg} \mathrm{ml}^{-1}$ bovine serum albumin and $0.625 \mathrm{mM} \mathrm{MgCl}_{2}$. PCR mixtures targeting Eukarya consisted of primers (528F and 1492R, 0.4 mM each),

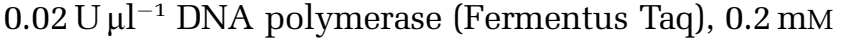
dNTPs (Fermentus), $0.1 \mathrm{mg} \mathrm{ml}^{-1}$ bovine serum albumin and $2 \mathrm{mM} \mathrm{MgCl}_{2}$. All mixtures included a final concentration of $1 \times$ of $\mathrm{MgCl}_{2}$-free buffer provided by the manufacturer with the Taq. Reactions were run in thermocyclers manufactured by either a PTC-100 programmable thermal controller (MJ Research, Waltham, MA, USA) or a PCR Express (Thermo Hybaid; Thermo Fisher Scientific, Pittsburgh, PA, USA) thermalcycler. For primer sets targeting Bacteria (8F with 1492R) and Eukaryotes (528F with 1492R) the cycles consisted of an initial melt at $94{ }^{\circ} \mathrm{C}$ for $3 \mathrm{~min}$, cycle reactions consisting of $30 \mathrm{~s}$ at $94{ }^{\circ} \mathrm{C}, 45 \mathrm{~s}$ at $50{ }^{\circ} \mathrm{C}$ for annealing and $1 \mathrm{~min}$ extensions at $72^{\circ} \mathrm{C}(25$ cycles for bacterial primers and 27 cycles for eukaryotic primers) with a final extension time of $3 \mathrm{~min}$ at $72{ }^{\circ} \mathrm{C}$. For primer sets targeting Archaea $(21 \mathrm{~F}$ with 915R) the cycles consisted of an initial melt at $94^{\circ} \mathrm{C}$ for $5 \mathrm{~min}, 30$ cycle reactions consisting of $30 \mathrm{~s}$ at $94^{\circ} \mathrm{C}$, 
Table 2 Oligonucleotide sequences for PCR primers

\begin{tabular}{lclll}
\hline Common primer name & Length (nucleotides) & Target & Nucleotide sequence $\left(5^{\prime} \rightarrow 3^{\prime}\right)$ & Reference \\
\hline $8 \mathrm{~F}^{\mathrm{a}}$ & 20 & Bacterial domain & AGAGTTTGATCCTGGCTCAG & Delong (1992) \\
$21 \mathrm{~F}$ & 20 & Archaeal domain & TTCCGGTTGATCCYGCCGGA & Delong (1992) \\
$528 \mathrm{~F}^{\mathrm{a}}$ & 15 & Eukaryotic domain & CGGTAATTCCAGCTC & Edgcomb et al. (2002) \\
$915 \mathrm{R}^{\mathrm{a}}$ & 20 & Archaeal domain & GTGCTCCCCCGCCAATTCC & Amann et al. (1990) \\
$1492 \mathrm{R}$ & 21 & All known life & ACGGYTACCTTGTTACGACTT & Fry et al. (1997) \\
\hline
\end{tabular}

aprimers that were labeled with 6-FAM during PCR for TRFLP.

$45 \mathrm{~s}$ at $62{ }^{\circ} \mathrm{C}$ for annealing and $1 \mathrm{~min} 30 \mathrm{~s}$ extensions at $72{ }^{\circ} \mathrm{C}$ with a final extension time of $5 \mathrm{~min}$ at $72{ }^{\circ} \mathrm{C}$. Reactions using primer 915R were run exclusively in the Hybaid thermocycler, as double banding occurred when using the same run conditions in the MJ Research thermocycler. Other primer sets were not found to be sensitive to variation between the two thermocyclers. The same optimized conditions, but without a labeled primer, were used to produce PCR products used in cloning reactions (described below).

\section{Terminal restriction fragment length polymorphism} analysis

PCR products with a 6-carboxyfluorescein (6-FAM)labeled primer were digested overnight with HhaI (GCG $\downarrow$ C) for bacterial and archaeal samples and HaeIII (GCC $\downarrow$ G) for eukaryotic samples. These restriction enzymes were selected because they produced the highest number of terminal restriction groups for the DePue PCR products when compared to other common restriction enzymes (data not shown). Replicates representing at least $10 \%$ of the samples processed were analyzed to assess the variability associated with each process step, including DNA extraction, PCR and gel analysis. Digested samples were cleaned using ethanol precipitation and analyzed with an internal size standard using an ABI 377 flat gel sequencer (Applied Biosystems, Inc., Carlsbad, CA, USA) at the Center for Gene Research and Biotechnology, Oregon State University, Corvallis, OR, USA. Process replicates were carried through the TRFLP data analysis process to evaluate experimental variation associated with the DNA extraction, PCR and restriction digestion steps. Resulting profiles were analyzed using DAx software (Van Mierlo Software Consultancy, Eindhoven, the Netherlands). Following conversion of the profile $x$ axis into bp units using the internal standard, the relative peak areas for terminal restriction fragments (TRFs) comprising at least $1 \%$ of the total area were recorded for each profile. TRFs were named for the average $x$ axis bp length at the maximum amplitude of the peak.

\section{Molecular cloning and sample sequencing}

PCR products were ligated into cloning vector using a TOPO TA Cloning kit by Invitrogen (Carlsbad, CA, USA). Vectors were transformed into One Shot TOP10 competent cells (also from Invitrogen).
Transformed cells were grown on Luria-Bertani agar plates with kanamycin. A total of 96 colonies were picked and stored for each cloning reaction. To recover plasmids, we incubated picked colonies overnight in Luria-Bertani broth at $37^{\circ} \mathrm{C}$, and collected plasmids using QIAprep Spin Miniprep kits (Qiagen Inc., Valencia, CA, USA). Approximately 50 clones each for the bacterial and archaeal PCR reactions, and 24 clones for the eukaryotic PCR reaction were screened. Recovered plasmids were sequenced with vector-based sequencing primers (M13F and M13R) using a MegaBase 96-capillary sequencer at the DNA Sequencing Center at the Marine Molecular Biotechnology Laboratory, University of Washington. Resulting sequences were screened for theoretical TRF lengths using Fragment Finder software, designed by Meredith Hullar and Erik Tribou. Sequences that matched targeted profiles TRFs were aligned against reference taxa from the June 2002 version of the arb PTServer and published environmental sequences identified by BLAST search (National Center for Biotechnology Information, http://www.ncbi.nlm.nih.gov/BLAST/). Alignment was carried out using arb alignment software (The ARB Project, Technical University Munich, Munich, Germany) (Ludwig et al., 2004). Aligned Crenarchaeota sequences were compiled into phylogenetic clusters by nearest neighbor using nucleotides between Escherichia coli positions 193-921, and the filter arc_rr5_june03. Sequences that did not have full coverage within this range were excluded from this initial tree-building step. Shorter sequences deemed important to data interpretation (for example, sequences from this study, or published sequences from other related studies) were added to the established tree one at a time by parsimony (using the same filter, and considering available nucleotides within the same range) and were flagged in the final figure to ensure proper data interpretation. Sequences from this study that were used to generate the phylogenetic tree were submitted to GenBank (ascension numbers GQ925435-GQ925445).

Theoretical TRF of previously published sequences The theoretical TRFs of previously published sequences were determined either by downloading the sequence information into Fragment Finder, or using the base numbers shown in the alignment editor of arb. In addition, the ribosomal database 
project (RDP) T-RFLP v1.0 Alpha 1 database was accessed on 11 December 2009 to screen for archaeal sequences potentially associated with a fragment length of 191, when processed with a labeled 915R primer and digested with HhaI (as described above for TRFLP analysis). Though no longer supported by the RDP, TAP TRFLP was accessed at the URL (http://rdp8.cme.msu.edu/html/TAP-trflp.html).

\section{$R N A$ extraction and hybridization}

RNA was extracted by bead-beating, phenolchloroform extraction and ethanol precipitation as previously described (MacGregor et al., 1997), except that a FastPrep 120A bead beater (BIO101; now MP Biomedical) was used for mechanical agitation for $20 \mathrm{~s}$ at speed setting 5. Additional parameters critical to RNA extraction are discussed elsewhere (Alm and Stahl, 2000; Alm et al., 2000). RNA from each extract was transferred to MagnaCharged membranes (Raskin et al., 1996) in duplicate using a computer-generated random distribution pattern and probed with radiolabeled oligonucleotides as described previously (Raskin et al., 1995). Membranes were prehybridized at $40{ }^{\circ} \mathrm{C}$ and washed at $44^{\circ} \mathrm{C}$ (S-*-Univ-1390-a-A-18), $56^{\circ} \mathrm{C}$ (S-D-Arch0915-a-A-20), $54{ }^{\circ} \mathrm{C}$ (S-D-Bac-338-a-A-18), $56{ }^{\circ} \mathrm{C}$ (S-DArch-0915-a-A-20) or $52^{\circ} \mathrm{C}$ (S-D-Euk-0516-a-A-16). Relative abundances of the measured rRNA were used for data analysis, because high concentrations of humic substances coextracted with RNA from sediment samples may compete with RNA binding to membranes, and thus, interfere with quantitative evaluation of RNA abundance (Alm et al., 2000).

\section{Influence of metals contamination on community similarities and diversities}

Diversity represented by each TRFLP profile was calculated using the Shannon-Weaver Diversity Index (Shannon and Weaver, 1949; Hill et al., 2003) and compared with metal concentrations. TRFLP profile similarities were analyzed by generating a matrix using the Bray-Curtis Similarity Index for logarithmically normalized relative abundance data (Hruby, 1987; Spellerberg, 1991) comparing all 30 processed samples and process control replicates. Similarity of metal concentrations was calculated as difference between the log-transformed concentrations (separately for pore water $\mathrm{Zn}$, As and $\mathrm{Mn}$, and total Zn-metals previously implicated in biomass loss at these sites; Gough et al., 2008a). The influence of metal concentration on the similarity of community structures was investigated by graphing the similarity of metal concentrations versus the similarity of TRFLP profiles for each sample pair.

\section{Correlation analysis}

Correlation analysis was conducted for each identified TRF that occurred in at least two of the field sites, using metal concentration or environmental parameter as the independent variable. Information from process replicates was averaged before correlation analysis. Data points representing the highest and lowest occurrence of an independent variable were removed from analysis to prevent undue bias by extreme data points. For each correlation analysis, if plotted residuals indicated that a normal variance was not achieved, the independent variable was log-normalized and the correlation was recalculated. Data points whose calculated residuals were greater than 3 were considered outliers, based on the recommendations of Hayter (1996). Correlations were deemed statistically significant if the slope parameter was not predicted to pass through zero within a 95\% confidence interval (CI) and the correlation coefficient $(r)$ was statistically significant at $\alpha=0.001$. The $95 \%$ CI of the correlation slope parameter $(\beta)$ and the significance of the correlation coefficient $(r)$ were calculated as described by Hayter (1996), respectively as:

$$
C I=\beta \pm \frac{\hat{\sigma} t_{\alpha / 2, n-2}}{\sqrt{\sum_{i=1}^{n}\left(x_{i}-\bar{x}\right)^{2}}} \quad t_{\alpha, n-2}=\frac{r \sqrt{n-2}}{\sqrt{1-r^{2}}}
$$

where $\sigma$ is the square root of the error variance, $t$ the critical point of the $t$-distribution, and $x$ the independent variable. As an example, under these condition and with $n=27$, statistical significance was indicated for squared correlation coefficients greater than $0.268\left(r>0.518\right.$ or $\left.R^{2}>0.268\right)$. Correlation results were considered inconclusive if more than two-thirds of the detected occurrences of a TRF had intensities $<3 \%$ of their profile peak area, because of potential bias in the correlation at levels close to the method detection limit.

\section{Results}

Terminal restriction fragment length polymorphism A total of 60 distinct TRFs were detected in the bacterial TRFLP profiles, whereas 46 and 41 TRFs were detecting in archaeal and eukaryotic profiles, respectively. The average number of TRFs observed in an individual TRFLP profile was 32, 10 and 19, respectively, for the bacterial, archaeal, and eukaryotic profiles. Most of these TRFs did not show correlation with metal concentrations or environmental parameters in the soils. TRFs that showed statistical correlation to metal concentrations or environmental parameters are shown in Table 3. Several TRFs were present at or near the TRFLP method detection limit so that their correlation analysis was not conclusive (these are listed in Supplementary Table S1). 


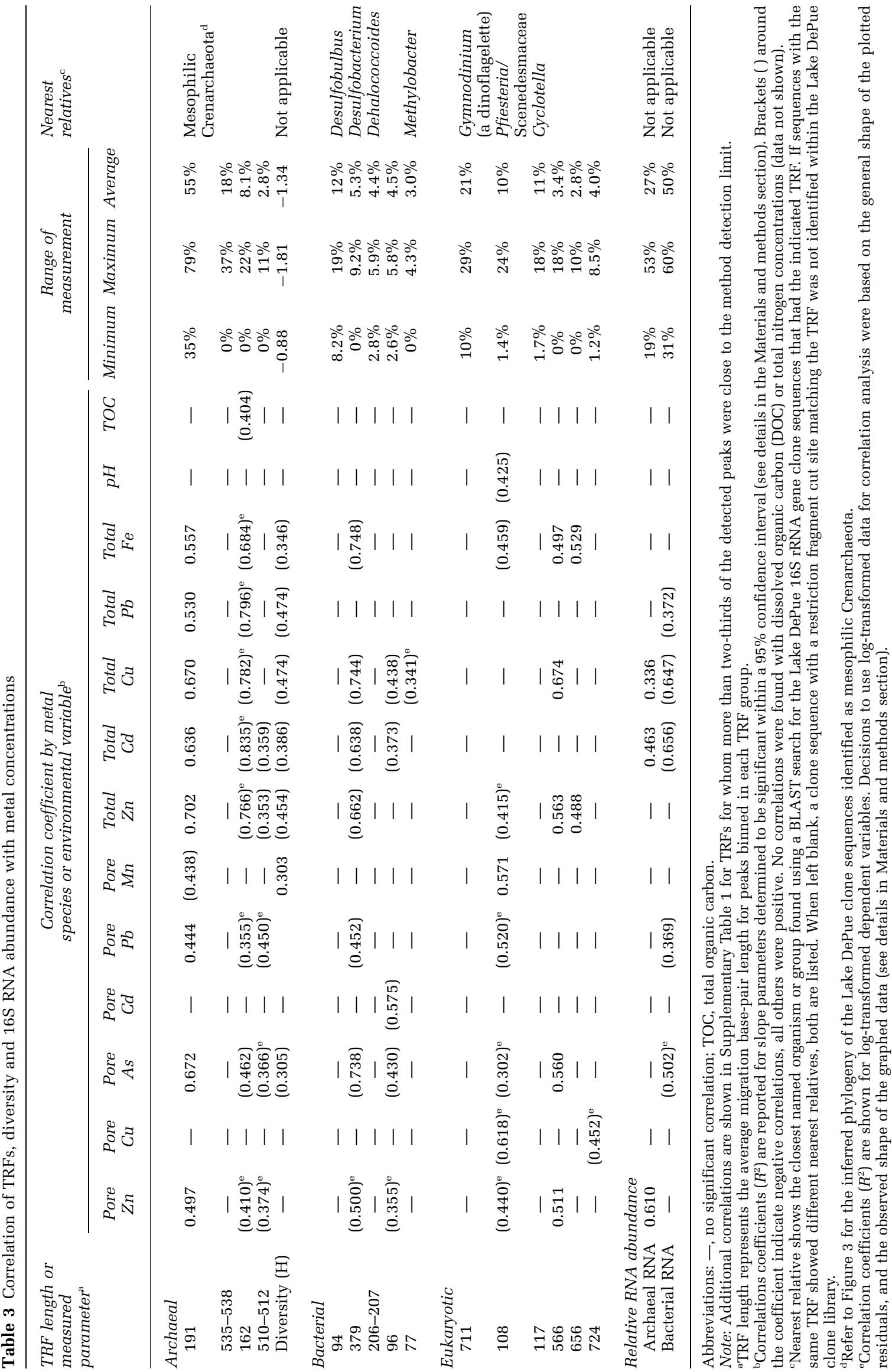


a

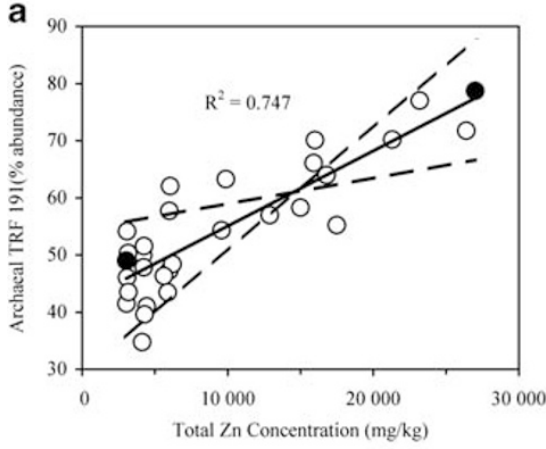

C
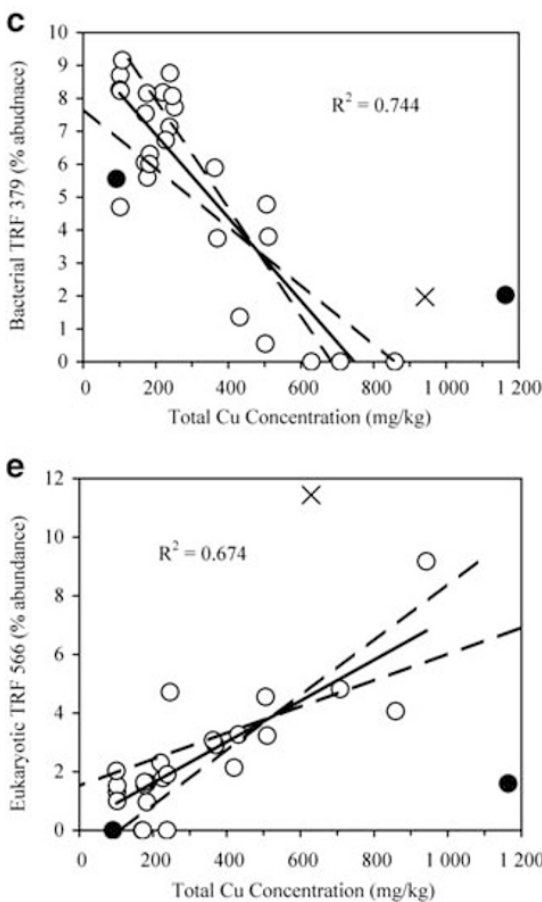
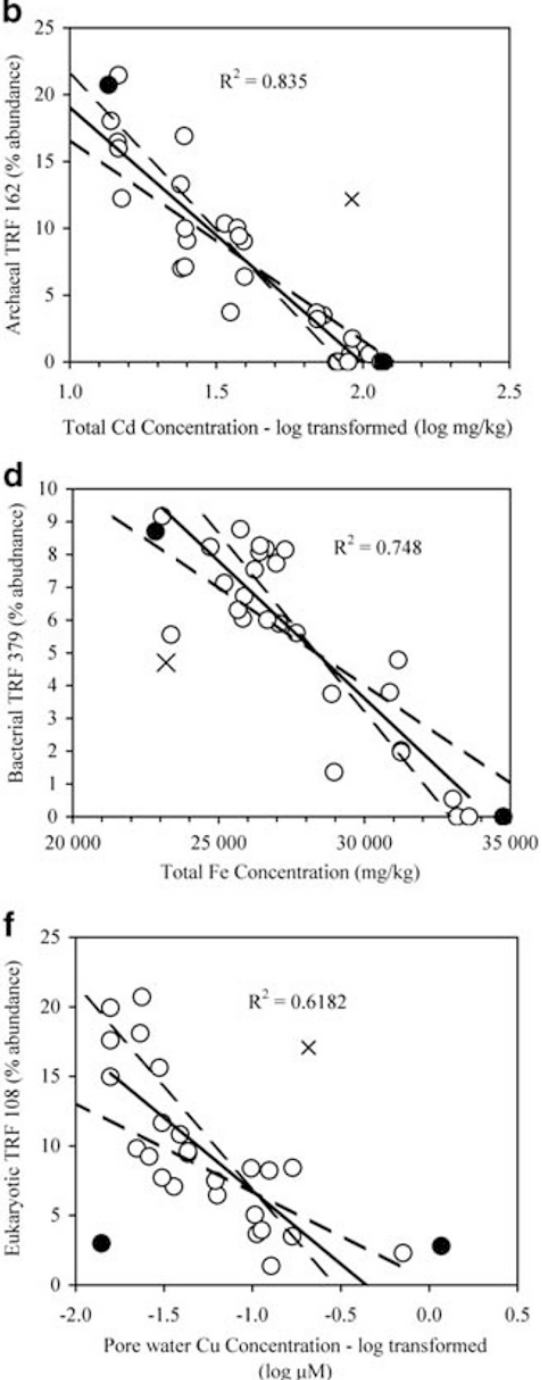

Figure 2 Correlation of metal contaminants with the relative abundance of select terminal restriction fragments (TRFs). Open circles $(O)$ indicate data points used for correlation analysis; closed circles $(0)$ indicate data from the highest and lowest metal concentration level; open $\mathrm{x}$ markers $(\times)$ show outlier data points whose standardized residuals were greater than 3 or less than $-3 ; r$-squared values $\left(R^{2}\right)$ show the squared Pearson's correlation coefficient. Solid lines show the correlation slope parameter; dashed lines the 95\% confidence interval of the slope parameter. For correlations with identified outliers, standardized residual plots are included in Supplementary Figure S2. For correlations where log-normalization was used to correct for inconsistent error variance or inappropriate model fitting, both standardized residual plots and correlation graphs with nontransformed data are included in Supplementary Figures S1 and S2. (a) Total Zn concentration versus archaeal TRF 191. (b) Log-transformed total Cd concentrations versus archaeal TRF 162. (c) Total $\mathrm{Cu}$ concentrations versus bacterial TRF 379. (d) Total Fe concentrations versus bacterial TRF 379. (e) Total Cu concentrations versus eukaryotic TRF 566; an additional outlier (not shown) was located at $502 \mathrm{mg} \mathrm{kg}^{-1} \mathrm{Cu}, 17.7 \%$ abundance. (f) Pore water $\mathrm{Cu}$ concentrations versus eukaryotic TRF 108.

\section{Correlation analysis and sequence cloning for} archaeal TRF

Of the 46 fragments detected in the archaeal profiles, $3(9 \%)$ showed significant correlation with metal concentration (Table 3). One additional archaeal TRF showed potential correlation, but was present at or just above the TRFLP detection limit (Supplementary Table S1). Fragment TRF 535-538 represented up to $37 \%$ of archaeal TRFLP peak area, but did not show correlation to any of the analyzed metals or environmental parameters. No sequences corresponding to TRF 535-538 were recovered among Lake DePue clones; however, TRF 535-538 was a common theoretical fragment length for Methanosarcinales in the RDP TAP-TRFLP database.

Archaeal TRF 191 was consistently the largest peak in the archaeal profiles, representing between $35 \%$ and $80 \%$ of the total peak area in the sample profiles. The relative abundance of archaeal TRF 191 was strongly correlated to total $\mathrm{Zn}$ concentrations (Figure 2a). Archaeal TRF 191 also correlated with concentrations of other metals including pore water As, total $\mathrm{Cu}$ and total Cd (Table 3). Lake DePue DNA clone sequence data that corresponded to 
archaeal TRF 191 clustered predominately with mesophilic Crenarchaeota sequences recovered from freshwater and anaerobic environments, and with lesser frequency with mesophilic Crenarchaeota sequences recovered from soils (Figure 3 ).

Archaeal TRF 162 was present at lower intensities than archaeal TRF 191 in all archaeal profiles. This TRF represented up to $21 \%$ of the total archaeal TRF abundance (Table 3), and was most significantly correlated with total Cd concentrations (Figure 2b). Strong correlations were also indicated with total $\mathrm{Pb}$, total $\mathrm{Cu}$, total $\mathrm{Zn}$ and total $\mathrm{Fe}$ concentrations, and weaker (though still statistically significant) correlations were indicated with pore water As, pore water $\mathrm{Zn}$ and pore water $\mathrm{Pb}$ (Table 3 ). In addition, this fragment showed a weak negative correlation with TOC concentrations in the sediments samples. This was the only fragment in the study to show a correlation with TOC. No sequences corresponding to TRF 162 were identified among Lake DePue clones; however, TRF162 was a common theoretical fragment length for Methanococcales and Methanobacteriales sequences in the RDP TAP-TRFLP database.

Correlation analysis and sequence cloning for Bacteria TRFLP

Of the 60 bacterial TRF detected, 3 fragments (5\%) showed significant correlation with metal concentrations (Table 3). An additional eight fragments $(13 \%)$, which were present at or just above the TRFLP method detection limits, showed potential correlation (Supplementary Table S1). Bacterial TRF 94 represented between $8 \%$ and $20 \%$ of the peak areas and bacterial TRF 206-207 represented between $3 \%$ and $6 \%$ of the peak areas in the bacterial TRFLP profiles; but neither of these showed correlation to any of the analyzed metals or environmental parameters. Lake DePue clone sequences that corresponded to bacterial TRF 94 and bacterial TRF 206-207 were identified as relatives of Desulfobulbus and Dehalococcoides, respectively.

Bacterial TRF 379 had the most significant correlation to metal concentrations among the bacterial fragments (Table 3). Interestingly, although negative correlations with pore water As and total Cu concentrations were highly significant, negative correlation with total Fe concentrations showed similar statistical significance (Figures 2c and d). Lake DePue clone sequences associated with bacterial TRF 379 were phylogenetically related to Desulfobacterium.

Bacterial TRF 96 showed lower (though still significantly relevant) correlation compared with bacterial TRF 379. Bacterial TRF 96 represented between $3 \%$ and $6 \%$ of the peak area in the bacterial TRFLP profiles. Significant negative correlations were observed for bacterial TRF 96 with pore water $\mathrm{Cd}$ and pore water As concentrations, and to a lesser extent with total $\mathrm{Cd}$ and pore water $\mathrm{Zn}$ concentrations (Table 3). A correlation plot for pore water $\mathrm{Cd}$ and bacterial TRF 96 is included in Supplementary Figure S1B.

Correlation analysis and sequence cloning for eukaryotic TRFLP

Of the 41 eukaryotic TRFs detected, 3 (7\%) showed significant correlation with metal concentration (Table 3). Additional two fragments $(5 \%)$ that were present at or just above the TRFLP method detection limits showed potential correlation, and are listed in Supplementary Table S1. Both Eukaryotic TRF 711 and TRF 117 had dominant peaks in the eukaryotic TRFLP profiles (Table 3); but, neither showed correlation to any of the analyzed metals or environmental parameters. Lake DePue clone sequences associated with eukaryotic TRFs 711 and 117 were identified respectively as relatives of Gymnodinium and Cyclotella.

Eukaryotic TRF 566 showed the most significant correlations with metal concentrations among the eukaryotic TRFs (Figure 2e). This fragment represented up to $18 \%$ of the relative TRF profile abundance (Table 3), and was not identified by clone sequences recovered from Lake DePue. Eukaryotic TRF 108 represented up to $24 \%$ of the total TRF abundance (Table 3), and was most correlated with pore water $\mathrm{Cu}$ (Figure 2f) and pore water $\mathrm{Mn}$ concentrations. Weaker (though still statistically significant) correlations were also indicated with several additional metals (Table 3 ). In addition, this fragment showed a weak negative correlation with pore water $\mathrm{pH}$. Only one other fragment showed potential correlation with $\mathrm{pH}$ (eukaryotic TRF 87), which is listed in Supplementary Table S1. Lake DePue clone sequences identified two phylogenetic groups associated with eukaryotic TRF 108, a dinoflagellate (genus Pfiesteria) and a green algae (family Scenedesmaceae).

\section{Community diversity and metal concentrations}

Shannon-Weaver diversity indices were greatest for the bacterial domain TRFLP profiles, followed by the eukaryotic domain and the archaeal domain (Figure 4a). Variation observed for the diversity indices calculated for the bacterial and eukaryotic TRFLP profiles did not correlate with concentrations of the analyzed metal fractions or environmental parameters. Archaeal profile diversity was most significantly correlated to total Zn concentration (Figure 5a). Weak correlations with archaeal profile diversity were also observed for other total metal concentrations, and for pore water concentration of As and Mn (Table 3).

\section{Correlation of community similarity and metals concentrations}

TRFLP profiles were highly similar. Archaeal TRFLP profiles showed the least similarity, with an average of $60 \%$ among all profiles, whereas 


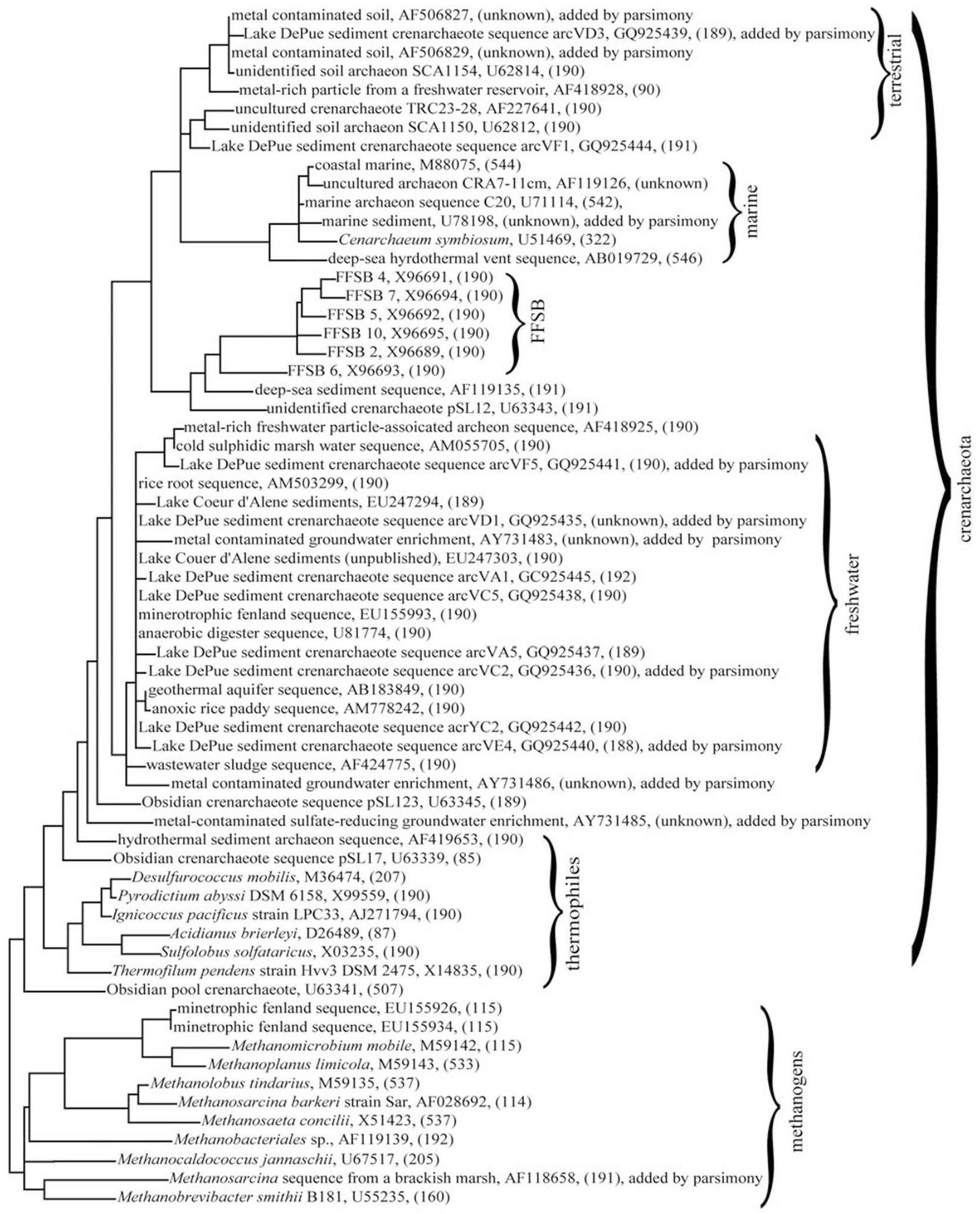

0.1

Figure 3 Nearest-neighbor tree showing the phylogenetic relatedness of Lake DePue clones (GQ925435-GQ925445) to Crenarchaeota and methanogenic sequences. Sequences are identified by name or description and accession number. The distance (in bp) from $915 \mathrm{R}$ to the first HhaI cut site (theoretical TRF) is indicated in parentheses for each sequence. 'unknown' indicates that a theoretical TRF length could not be determined because the 915R priming site was not included in the sequence; 'added by parsimony' indicates that the sequence was added after the initial tree construction because the sequence coverage was not complete within the range used to generate the tree. 

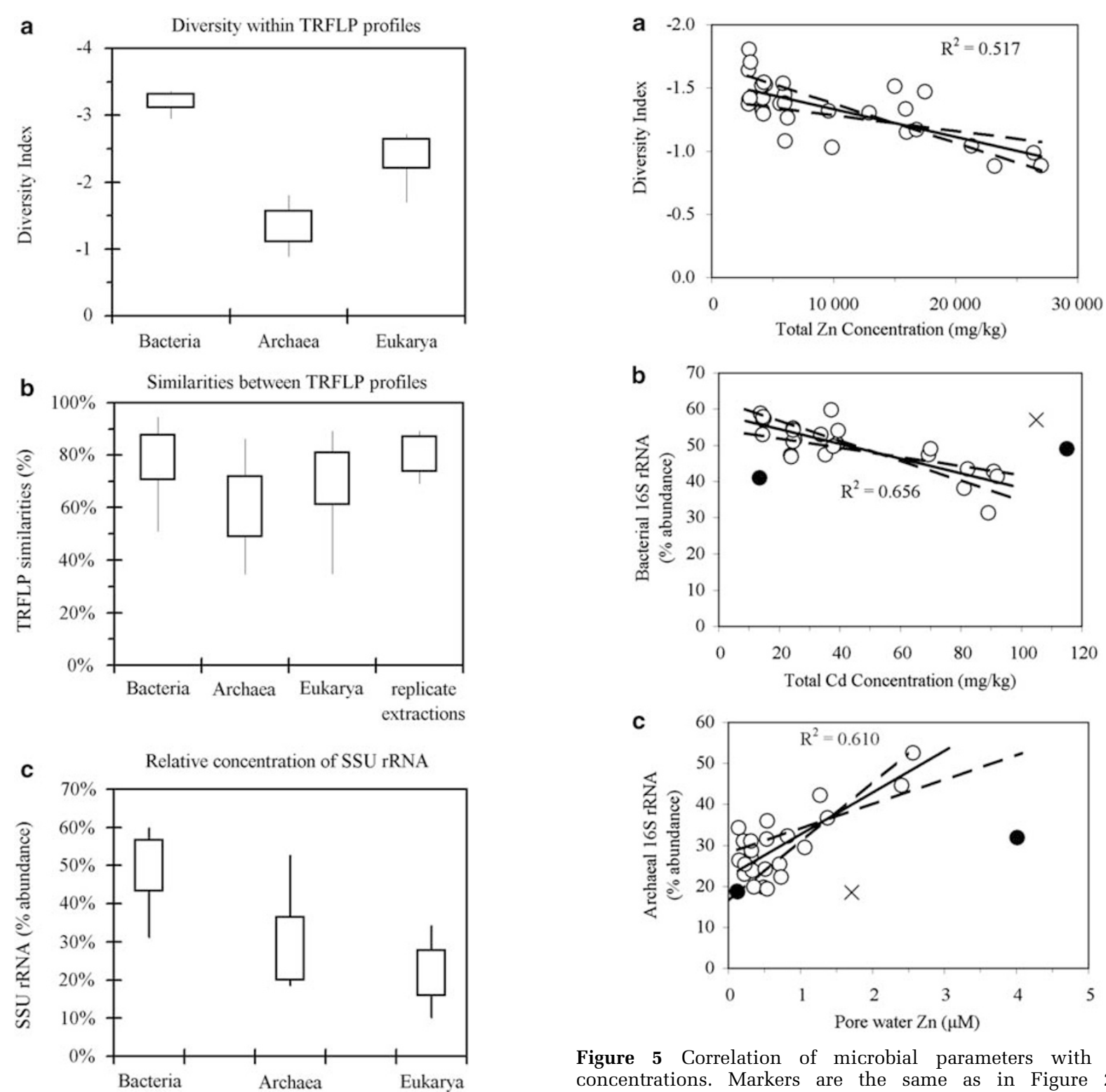

Figure 4 Ranges of diversity and similarities of TRFLP profiles, and the relative small subunit (SSU) rRNA abundance for each domain. Bars show the average \pm 1 standard deviation $(n=30)$. Lines show the range of the recorded values. (a) Diversity for TRFLP profiles. (b) Similarities between TRFLP profiles, compared to method controls. (c) Relative abundance of domain-level SSU rRNA in sediment samples from Lake DePue.

bacterial TRFLP profile similarity values were similar to those calculated for DNA extraction replicates (Figure 4b). TRFLP profile similarities of replicates determined separately at the DNA extraction, PCR and enzyme restriction steps are presented for each primer set in Supplementary Figure S3. Comparison of archaeal TRFLP profile similarities to relative metal concentration revealed a statistically significant trend within a 95\% CI (Supplementary Figure S4). Trends for the bacterial and eukaryotic profiles were overly influenced by samples collected from a single sampling site, so that correlations
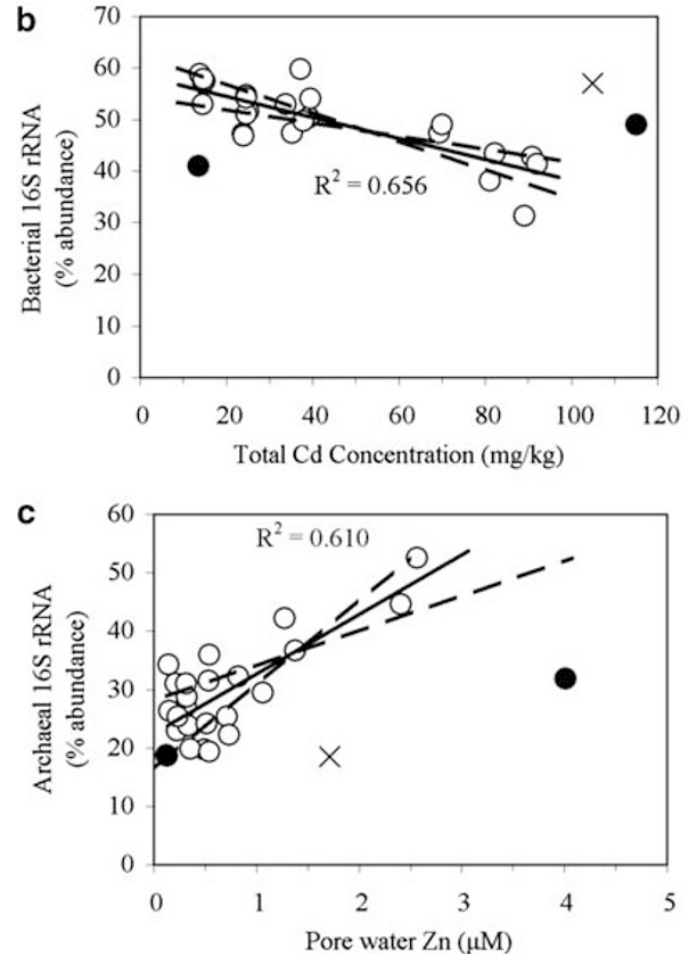

Figure 5 Correlation of microbial parameters with metal concentrations. Markers are the same as in Figure 2. (a) Shannon-Weaver Diversity Index of archaeal TRFLP profiles versus total $\mathrm{Zn}$ concentration. (b) Total bacterial 16S rRNA versus total Cd concentration. (c) Total archaeal 16S rRNA versus pore water $\mathrm{Zn}$ concentration.

could not be definitively determined (data not shown).

\section{Domain-level rRNA quantification}

To evaluate if the relative stability observed within domain-level community TRFLP profiles might conceal a shift in abundance among the domains, we used domain-specific probes to quantify the relative proportion of SSU rRNA attributable to each domain. Bacterial rRNA showed highest relative abundance in the samples, followed by archaeal rRNA and eukaryotic rRNA (Figure 4c). The relative abundance of the domain-rRNA did not change 
among sampling sites (analysis of variance, $\alpha=0.05$ ) - likely influenced by noise from the high metal variance among samples collected from a single site-or in correlation with most metal concentrations (95\% CI; data not shown). Exceptions included statistically significant correlation between relative archaeal rRNA abundance with pore water $\mathrm{Zn}$ concentrations (Figure 5b) and to a lesser extent with total $\mathrm{Cd}$ and $\mathrm{Cu}$ concentrations (Table 3), and correlation between relative bacterial rRNA abundance with total $\mathrm{Cd}$ concentrations (Figure 5c) and to a lesser extent with pore water $\mathrm{As}$ and $\mathrm{Pb}$ and total $\mathrm{Cu}$ and $\mathrm{Pb}$ (Table 3).

\section{Public database survey for potential identification of archaeal TRF 191}

All the archaeal sequences in the RDP TAP TRFLP database (594 total) were screened for their theoretical TRF when primed with a labeled 915R primer and digested with HhaI. Of these 594 sequences, 423 represented the Euryarchaeota and 169 represented the Crenarchaeota. The Korarchaeota and Nanoarchaeota were not represented in the database. Among the Euryarchaeota sequences, TRF 191 ( $\pm 5 \mathrm{bp}$ ) occurred four times $(<1 \%$ of the Euryarchaeota sequences); two of these sequences are represented in Figure 3 (ascension numbers AF1186558 and AF119139). Common cut sites for the Euryarchaeota were TRF 162 (30\%), which was particularly common among the Methanococcales and Methanobacteriales, as well as with the Methanosaeta and Methanosarcina genera within the Methanomicrobacteria.

Examination of Crenarchaeota sequences revealed a much higher occurrence of TRF 191. The RDP TAP TRFLP database included 89 sequences representing the nonthermophilic marine subgroups, and 80 sequences representing the thermophilic Crenarchaeota. Of the 89 nonthermophilic sequences, $16(18 \%)$ sequences had theoretical TRF of 191 ( $\pm 5 \mathrm{bp}$ ); all within the subgroup designated 4B7 of the marine Crenarchaeota. Other common TRF lengths among the marine Crenarchaeota were TRF 545-547 (50\%) and TRF 325 (10\%). Among the thermophilic Crenarchaeota sequences, 54 of the 80 sequences $(68 \%)$ had theoretical TRF of 191 ( $\pm 5 \mathrm{bp}$ ). The next most common TRF length for the thermophilic Crenarchaeota was TRF 86 (11\% of the sequences), which was particularly common among the Acidianus subgroup. Mesophilic freshwater, FFSB, and terrestrial Crenarchaeota sequences were not represented in the RDP TAP TRFLP database.

\section{Discussion}

Although it has been documented that metal stress impacts microbial community structures in aerobic environments (Bååth, 1989; Smit et al., 1997; Sandaa et al., 2001), less is known about how metal contamination affects anaerobic sediment microbial communities. The primary goal of this work was to address whether following long-term metals exposure microbial community structures in anoxic sediments differed in correlation to metal contamination levels. Thirty sediment samples representing a large range of contamination levels were collected from a single lake on a single day to allow experimental examination of differences related to metal contamination levels while limiting temporal and large-scale geographic noise (such as temperature fluctuations, nutrient influxes related to storm events and seasonal influences on lake productivity). Similar experimental approaches have been successfully used to establish statistical impacts by metals to soil bacterial communities (Konopka et al., 1999; Becker et al., 2006). In the Lake DePue sediments, several TRFs showed statistical correlation with sediment metal concentrations, suggesting potential community impacts. However, contrary to expectation, the majority of observed TRFs showed no variation with metal contamination levels, and community similarity remained high among samples with vastly differing metals contamination levels.

Biomass was previously documented to decline in these sediments by approximately $90 \%$ across the metal contamination gradient (Gough et al., 2008a); yet, strong similarities among TRFLP profiles (Figure 4b) reflected a consistent occurrence of the majority of detected fragments. In fact, $89 \%$ of the archaeal, $75 \%$ of the bacterial and $73 \%$ of the eukaryotic TRFs showed no correlations with metal concentrations or other measured site parameters, including dominant peaks such as bacterial TRF 94 (a putative Desulfolobus relative), and eukaryotic TRF 711 (a putative Gymnodinium relative, Table 3). Despite high similarities indicated within each domain by the TRFLP profiles, potential population shifts between the domains were indicated by the correlation of bacterial and archaeal rRNA with some metals (Table3; Figures 5b,c) and a potential trend was detected for archaeal profile similarities in relation to metal contamination levels (Supplementary Figure S4). Mathematically, observations of lower proportions of bacterial rRNA, higher proportions of archaeal rRNA, higher dominance of Crenarchaeota within the Archaea and simultaneous lower total biomass concentrations, all with increased metal contamination, might be explained by: (1) a similar biomass loss among the bacterial and eukaryotic and non-Crenarchaeota archaeal populations and (2) a much lesser reduction of Crenarchaeota biomass. However, these finding are in direct contrast to established ecological theories. Among his 'Trends expected in stressed ecosystems', Odum (1985) predicted that in stressed ecosystems species diversity would decrease and dominance of a few species would increase. Schindler (1990) modified Odum's list to add that sensitive species are expected to be lost whereas 
tolerant species become more dominant. This response was observed for some populations in Lake DePue (Table 3), though not at an expected scale as most TRF showed no correlation to metal concentrations. In addition, metal contamination was only associated with a decline in diversity among the archaeal profiles (Figure 5a; bacterial and eukaryotic trends; data not shown). In contrast to the results reported here, a preponderance of previous reports have shown significant bacterial community shifts with comparatively low metal stress levels (Frostegård et al., 1996; Bååth et al., 1998a; Konopka et al., 1999; Sandaa et al., 1999a). There are several differences, however, between these previous works and the current study. First, sediments in this study were anoxic, and therefore examined inherently different microbial communities in the soils previously examined. Second, Zn, metal concentrations in Lake DePue (summarized in Table 1 and shown in detail in Gough et al., 2008a ) were generally higher than in previous studies. Interestingly, two previous studies with similar $\mathrm{Pb}$ (Grandlic et al., 2006) or $\mathrm{Cu}$ (Konstantinidis et al., 2003) contamination levels also reported minimal apparent influence of contamination levels on bacterial community structure. These results seem in apparent disagreement with a model proposed by DiazRavina and Bååth (1996) in which biomass loss associated with the death of metal-sensitive microbes is replaced by the growth of metal-tolerant microbes resulting in community succession with no associated biomass loss. As an extension to this earlier model, once a metal-tolerant community is established (such as at the lowest level of metal contamination examined in this study), further metals stress might lead to a loss of biomass without an associated community shift (as documented in this study). Further study of highly metal-impacted sediments will elucidate the accuracy of this modified metal-stress model.

Correlation analysis was used to reveal discernible influences of metal contamination level on the resulting microbial community, as shown in Table 3 and Figure 2. Methods such as principle component analysis or hierarchical cluster analysis, which are commonly used to examine TRFLP data, separate and cluster profiles based on calculated similarities. The high similarity among the Lake DePue sediment profiles was not conducive to this type of statistical separation (data not shown). Using an alternative approach, correlation analysis revealed several individual TRFs statistically correlated to metal contamination levels (Table 3).

Correlation analysis revealed several putative populations that suggest interesting hypotheses for potential future study, particularly as implications of the measured population differences to ecological function of the sediments were not readily apparent. For example, implications to sulfate reduction within the sediments could not be inferred based on the community analysis data as putative representatives of the sulfate-reducing bacteria showed different responses to metal contamination levels.
Specifically, a negative correlation was indicated for a putative Desulfobacterium population (bacterial TRF 379; Figure 2c; Table 3) whereas no discernable pattern was indicated for a dominant bacterial TRF associated with Desulfobulbus (bacterial TRF 94; Table 3). This result is of particular interest considering that enhanced sulfate reduction rates were previously reported for the sediments from the most contaminated site in Lake DePue (Gough et al., 2008b). Of additional interest was the negative association of bacterial TRF 379 (putative Desulfobacterium) with $\mathrm{Fe}$ concentrations (Figure 2d). Desulfobacterium is associated with iron oxidation coupled with sulfate reduction when organic electron donors are unavailable (Dinh et al., 2004). However, this process may not be occurring in Lake DePue sediments because both TOC and DOC were plentiful (Table 1) and because the negative correlation indicated (Table 3), suggesting that $\mathrm{Fe}$ was not a rate-limiting substrate. Thus, much remains to be learned about the ecological roles and interactions of sediment microbial communities in contaminated environments.

Among the many correlations observed in this study, perhaps most interesting were within the archaeal domain, in which a TRF for the Crenarchaeota dominated the TRFLP patterns (archaeal TRF 191; Table 3) and showed a strong positive correlation with metal contamination (Figure 2a). The dominance of the Crenarchaeota in Lake DePue sediments suggested that methanogens-the archaeal population typically expected to dominate freshwater sediments (Pedersen and Sayler, 1981; Boon et al., 1996) - may not have been competitive in these metal-contaminated sediments. In fact, archaeal TRF 162, which was putatively associated with Methanococcales/Methanobacteriales families, showed negative correlation with metal contamination (Figure 2b). This is the second report of an anoxic metal-contaminated environment whose archaeal community showed crenarchaeota dominance and repressed methanogen populations (Geets et al., 2006), and a first report for this trend in a natural setting.

Because of the important implications of Crenarchaeota enrichment in correlation with metal contamination levels, three independent approaches were used to identify phylogenetic groups potentially associated with archaeal TRF 191. First, cloned archaeal sequences recovered from Lake DePue sediments were screened for both their phylogenetic association and theoretical TRFLP cut site. This was the most significant identification, as it established the presence of Crenarchaeota sequences directly associated with the study sediments. Second, sequences used to generate Figure 3 were screened for their theoretical cut sites, including sequences retrieved from public databases. These results are summarized by showing the theoretical fragment lengths in Figure 3, though many additional sequences were screened that were 
not be included in the final figure. The third approach used was to screen all archaeal sequences in the RDP TAP-TRFLP database. Although the target Crenarchaeota group was not represented in the RAP TAP-TRFLP database, this third screening was useful to show that archaeal TRF 191 was not commonly representative of other Archaeaspecifically the methanogens. In conclusion, archaeal TRF 191 was associated with the marine, thermophilic, freshwater and terrestrial clades of the Crenarchaeota, and therefore, based on the environment from which the sediments were retrieved, in this study archaeal TRF 191 most probably represented freshwater and terrestrial Crenarchaeota.

Much remains to be learned about the Crenarchaeota. The Crenarchaeota, a kingdom of the Archaea, were once thought to consist only of extreme thermophiles, and were first reported to inhabit freshwater lake sediments in the 1990s (Hershberger et al., 1996; MacGregor et al., 1997). Since that time, the genetic biomarkers for this clade have been detected in oceans, open waters, aquarium waters and soils (Kemnitz et al., 2007; Auguet and Casamayor, 2008). Great advances were recently made through the discovery that some members of this clade were capable of ammonia oxidation (Konneke et al., 2005; DeLong et al., 2006), whereas the function of other mesophilic Crenarchaeota remains unknown (Hamberger et al., 2008; Pouliot et al., 2009). In particular, little is currently known about the anaerobic freshwater mesophilic clade of the Crenarchaeota (Robertson et al., 2005; Lliros et al., 2008), or the potential influence of metal contamination on this microbial group. Crenarchaeota sequences have previously been detected in association with Fe-Mn-rich freshwater particles (Stein et al., 2002), and in an enrichment from metal-contaminated groundwater (Geets et al., 2006). Metal-contaminated sludge has been reported to decrease the survival and/or growth of aerobic soil Crenarchaeota (Sandaa et al., 1999a). Although this is contrary to the findings in this study, anaerobic Crenarchaeota may respond to metals stress differently than aerobic Crenarchaeota. Of additional interest, although in several extreme thermophilic environments Archaea dominate microbial communities, in most mesophilic environments Archaea represent about $10 \%$ of the microbial life (Robertson et al., 2005), whereas in the metalcontaminated sediments of Lake DePue not only did the Crenarchaeota dominate the archaeal populations, but the archaeal rRNA also represented $28 \%$ of the total sediment rRNA (Figure 4c).

Crenarchaeota phylogeny based on 16S rRNA gene sequences suggest relations associated with habitat, and from this clustering four major clades of the mesophilic Crenarchaeota have been suggested: freshwater, FFSB (a forest soil in Finland), marine and terrestrial (Buckley et al., 1998). This clustering is shown in Figure 3, with some apparent mixing between the terrestrial and freshwater clades. Phylogenetic clustering was not observed for Crenarchaeota sequence data recovered from heavy metal-contaminated sites. For example, within the freshwater Crenarchaeota cluster were sequences recovered from the metal-contaminated sediments of Lake Coeur d'Alene (EU247294 and EU247303 are shown in Figure 3) and sequences recovered from sites with no reported metal contamination including anoxic rice paddy, and an anaerobic digester. In fact Crenarchaeota sequences recovered from a single metal-stressed sample often show wide diversity, such as the Crenarchaeota metal-associated sequences recovered by Geets et al. (2006) from a sulfate-enrichment established to precipitate metals (AY731478 to AY731487, shown in Figure 3). One of these sequences, AY731483, clustered with freshwater Crenarchaeota in close association to several sequences recovered from Lake DePue (Figure 3), whereas AY731485 and AY73486 clustered among sequences obtained from Obsidian Pool in Yellowstone National Park. Another Lake DePue sequence (GQ925439; Figure 3), which was recovered from the most contaminated sediments examined in Lake DePue (Site 1), clustered among the terrestrial Crenarchaeota clade, and was related to sequences recovered from a metalexposure study (AF506827 and AF506829; Figure 3) as well as to a sequence recovered from soil with no reported metal contamination (U62814; Figure 3). Based on the names used to describe the environments from which the freshwater sequences were recovered, many appeared to be anoxic (for example, rice paddy and anaerobic digester). However, as yet there is not enough sequence data available to determine if there is a specific anaerobic clade of the Crenarchaeota.

In this study, both pore water and total metal concentrations were considered to account for direct interactions with bioavailable metal species and unidentified secondary effects that might be associated with nonlabile metal fractions. In several instances, strongest correlations were indicated with total metal concentrations, rather than with the more bioavailable pore water metal fractions. This result in Lake DePue sediments was similar to the result that Kamitani et al. (2006) reported for historically contaminated floodplain soils, where soils with higher total $\mathrm{Cu}, \mathrm{Zn}$ and $\mathrm{Pb}$ showed lower functional diversity and higher $\mathrm{Cu}$ stress tolerance than control soils, even though more labile metal fractions showed similar concentrations between their four sites. These results highlight the complex nature of microbial community adaptation to long-term metal exposure, and suggest that further field-based studies of chronically exposed populations may be needed to elucidate the interactions between metal fractionation and population diversity.

As more molecular-based methods become available for examining the microbial communities in 
environmental samples, it is important to select methods suited to the intended experimental questions. Because this study represented a first molecular characterization of anoxic metal-contaminated sediments, TRFLP was selected to compare relative abundance of major populations while allowing detection of potentially unexpected or yet-uncharacterized groups. When testing hypotheses about major changes to populations, TRFLP allows processing of relatively large numbers of samples and can eliminate noise associated with natural variability among less dominant groups, as evidenced by correlations presented in Table 3 even as community similarity for the samples remained relatively unchanged. In addition, because the TRFLP analysis was conducted with general domain-level primers, correlations were reported with an unexpected group, the Crenarchaeota (Table 3; Figure 3). Before experimentation, no evidence suggested that a Crenarchaeota population might be prevalent in the metal-contaminated anoxic sediments of Lake DePue. Had methods been used that rely on probes designed to target specific populations and clades, these experiments might easily have missed this poorly characterized mesophilic freshwater Crenarchaeota population. Still, when interpreting TRFLP results, the resolution of the method should be considered, which is limited to the major populations and thus can underestimate the full diversity of a community. In addition, although some fine-scale resolution is inevitably lost by TRFLP (for example, eukaryotic TRF 108 was found to represent multiple groups, Table 3; and archaeal TRF 191 represented both the freshwater and terrestrial clades of the kingdom Crenarchaeota, Figure 3), TRFLP allowed rapid processing of more than 30 samples in a timely and economic manner. As increased information becomes available about previously uncategorized groups, the scientific community will be better equipped to use TRFLP to predict and monitor community response to environmental contamination.

This study has shown that long-term exposure to varying levels of metal contamination may influence select individual microbial populations while not resulting in overtly large shifts in community structure. Detection of the poorly characterized anaerobic mesophilic Crenarchaeota in relatively high abundance in Lake DePue sediments leads to several potentially interesting directions for future study, particularly as the metabolic role of this population is yet to be determined. As more data become available, it will be interesting to determine if the Crenarchaeota are common in other eutrophic and anoxic freshwater sediments, or if their presence is somehow enhanced by metals contamination. Lake DePue, or other highly metalcontaminated sites, may serve as good field sources to potentially discover the biogeochemical role of this unexplored microbial group.

\section{Acknowledgements}

This work was supported by the United States National Science Foundation Grant MCB: 9807697 (DAS), the NABIR program within United States Department of Energy (DOE) (DAS) and the Virtual Institute for Microbial Stress and Survival (http://VIMSS.lbl.gov) supported by the US DOE, Office of Science, Office of Biological and Environmental Research, Genomics Program: GTL through contract DE-AC02-05CH11231 between Lawrence Berkeley National Laboratory and the US DOE (DAS). A 'Select Professions Dissertation Fellowship' from the American Association of University Women (AAUW) provided additional support to HLG. We thank Amy Dahl, Samuel Webb, Edward Peltier, Bradley Jackson, Grant Ferris and Melissa Nolan for assistance with field sampling; Lutgarde Raskin and Dominic Frigon for training and assistance with RNA membrane hybridization; Seana Davidson for extended discussion on optimizing TRFLP and Anne Bernhard for providing Parker River sediments used as washing experiment controls.

\section{References}

Alm EW, Stahl DA. (2000). Critical factors influencing the recovery and integrity of rRNA extracted from environmental samples: use of an optimized protocol to measure depth-related biomass distribution in freshwater sediments. J Microbiol Methods 40: 153-162.

Alm EW, Zheng DD, Raskin L. (2000). The presence of humic substances and DNA in RNA extracts affects hybridization results. Appl Environ Microbiol 66: 4547-4554.

Amann RI, Krumholz L, Stahl DA. (1990). Fluorescentoligonucleotide probing of whole cells for determinative, phylogenetic, and environmental-studies in microbiology. J Bacteriol 172: 762-770.

Aslibekian O, Moles R. (2003). Environmental risk assessment of metals contaminated soils at silver mines abandoned mine site, Co Tipperary, Ireland. Environ Geochem Health 25: 247-266.

Auguet JC, Casamayor EO. (2008). A hotspot for cold Crenarchaeota in the neuston of high mountain lakes. Environ Microb 10: 1080-1086.

Bååth E. (1989). Effects of heavy-metals in soil on microbial processes and populations (a review). Water Air Soil Pollut 47: 335-379.

Bååth E, Diaz-Ravina M, Frostegard A, Campbell CD. (1998a). Effect of metal-rich sludge amendments on the soil microbial community. Appl Environ Microbiol 64: 238-245.

Bååth E, Frostegard A, Diaz-Ravina M, Tunlid A. (1998b). Microbial community-based measurements to estimate heavy metal effects in soil: the use of phospholipid fatty acid patterns and bacterial community tolerance. AMBIO 27: 58-61.

Becker JM, Parkin T, Nakatsu CH, Wilbur JD, Konopka A. (2006). Bacterial activity, community structure, and centimeter-scale spatial heterogeneity in contaminated soil. Microb Ecol 51: 220-231.

Billen G. (1982). Modeling the processes of organic matter degradation and nutrients recycling in sedimentary systems. In: Nedwell DB and Brown CM (eds). Sediment Microbiology. Academic Press: New York, New York, pp 15-52. 
Boon PI, Virtue P, Nichols PD. (1996). Microbial consortia in wetland sediments: a biomarker analysis of the effects of hydrological regime, vegetation and season on benthic microbes. Mar Freshw Res 47: 27-41.

Buckley DH, Graber JR, Schmidt TM. (1998). Phylogenetic analysis of nonthermophilic members of the kingdom Crenarchaeota and their diversity and abundance in soils. App Environ Microbiol 64: 4333-4339.

Cahill RA, Bogner WC. (2002). Investigation of Metal Distributions and Sedimentation Patterns in Lake DePue and Turner Lake, RR-98. Illinois Waste Management and Research Center: Champaign, Illinois.

Capone DG, Reese DD, Kiene RP. (1983). Effects of metals on methanogenesis, sulfate reduction, carbon dioxide evolution, and microbial biomass in anoxic salt marsh sediments. Appl Environ Microbiol 45: 1586-1591.

DeLong E, Hallam S, Mincer T, Schleper C, Preston C, Roberts $\mathrm{K}$ et al. (2006). Pathways of carbon assimilation and ammonia oxidation suggested by environmental genomic analyses of marine Crenarchaeota. PLoS Bio 4: 2412-2412.

DeLong EF. (1992). Archaea in coastal marine environments. Proc Natl Acad Sci USA 89: 5685-5689.

DiazRavina M, Bååth E. (1996). Development of metal tolerance in soil bacterial communities exposed to experimentally increased metal levels. Appl Environ Microbiol 62: 2970-2977.

Dinh HT, Kuever J, Mussmann M, Hassel AW, Stratmann M, Widdel F. (2004). Iron corrosion by novel anaerobic microorganisms. Nature 427: 829-832.

Edgcomb VP, Kysela DT, Teske A, Gomez AD, Sogin ML. (2002). Benthic eukaryotic diversity in the Guaymas Basin hydrothermal vent environment. Proc Natl Acad Sci USA 99: 7658-7662.

Frostegård A, Tunlid A, Bååth E. (1996). Changes in microbial community structure during long-term incubation in two soils experimentally contaminated with metals. Soil Biol Biochem 28: 55-63.

Fry NK, Fredrickson JK, Fishbain S, Wagner M, Stahl DA. (1997). Population structure of microbial communities associated with two deep, anaerobic, alkaline aquifers. Appl Environ Microbiol 63: 1498-1504.

Geets J, Vanbroekhoven K, Borremans B, Vangronsveld J, Diels L, Van der Lelie D. (2006). Column experiments to assess the effects of electron donors on the efficiency of in situ precipitation of $\mathrm{Zn}, \mathrm{Cd}$, Co and $\mathrm{Ni}$ in contaminated groundwater applying the biological sulfate removal technology. Environ Sci Poll Res 13: $362-378$.

Gough HL, Dahl AL, Nolan MA, Gaillard J-F, Stahl DA. (2008a). Metal impacts on microbial biomass in the anoxic sediments of a contaminated lake. J Geophys Res Biogeosci 113: G020217.

Gough HL, Dahl AL, Tribou E, Noble PA, Gaillard JF, Stahl DA. (2008b). Elevated sulfate reduction in metalcontaminated freshwater lake sediments. J Geophys Res Biogeosci 113: G04037.

Grandlic CJ, Geib I, Pilon R, Sandrin TR. (2006). Lead pollution in a large, prairie-pothole lake (Rush Lake, WI, USA): Effects on abundance and community structure of indigenous sediment bacteria. Environ Pollut 144: 119-126.

Hamberger A, Horn MA, Dumont MG, Murrell JC, Drake HL. (2008). Anaerobic consumers of monosaccharides in a moderately acidic fen. Appl Environ Microbiol 74: 3112-3120.
Hassen A, Saidi N, Cherif M, Boudabous A. (1998). Resistance of environmental bacteria to heavy metals. Bioresour Technol 64: 7-15.

Hayat S, Ahmad I, Azam ZM, Ahmad A, Inam A, Samiullah. (2002). Effect of long-term application of oil refinery wastewater on soil health with special reference to microbiological characteristics. Bioresour Technol 84: 159-163.

Hayter AJ. (1996). Probability and Statistics for Engineers and Scientists. International Thomson Publishing: Boston, Massachusetts.

Helmisaari HS, Derome J, Fritze H, Nieminen T, Palmgren K, Salemaa $\mathrm{M}$ et al. (1995). Copper in Scots pine forests around a heavy-metal smelter in south-western Finland. Water Air Soil Pollut 85: 1727-1732.

Hershberger KL, Barns SM, Reysenbach AL, Dawson SC, Pace NR. (1996). Wide diversity of Crenarchaeota. Nature 384: 420-420.

Hill TCJ, Walsh KA, Harris JA, Moffett BF. (2003). Using ecological diversity measures with bacterial communities. FEMS Microbiol Ecol 43: 1-11.

Holmer M, Storkholm P. (2001). Sulphate reduction and sulphur cycling in lake sediments: a review. Freshw Biol 46: 431-451.

Hruby T. (1987). Using similarity measures in benthic impact assessments. Environ Monit Assess 8: 163-180.

Ingvorsen K, Zeikus JG, Brock TD. (1981). Dynamics of bacterial sulfate reduction in a eutrophic lake. Appl Environ Microbiol 42: 1029-1036.

Jensen DL, Holm PE, Christensen TH. (2000). Soil and groundwater contamination with heavy metals at two scrap iron and metal recycling facilities. Waste Manage Res 18: 52-63.

Jones JG. (1982). Activities of aerobic and anaerobic bacteria in lake sediments and their effect on the water column. In: Nedwell DB and Brown CM (eds). Sediment Microbiology. Academic Press: New York, New York, pp 107-145.

Kamitani T, Oba H, Kaneko N. (2006). Microbial biomass and tolerance of microbial community on an aged heavy metal polluted floodplain in Japan. Water Air Soil Pollut 172: 185-200.

Kejnovsky E, Kypr J. (1997). DNA extraction by zinc. Nucleic Acids Res 25: 1870-1871.

Kemnitz D, Kolb S, Conrad R. (2007). High abundance of Crenarchaeota in a temperate acidic forest soil. FEMS Microbiol Ecol 60: 442-448.

Konneke M, Bernhard AE, de la Torre JR, Walker CB, Waterbury JB, Stahl DA. (2005). Isolation of an autotrophic ammonia-oxidizing marine archaeon. Nature 437: 543-546.

Konopka A, Zakharova T, Bischoff M, Oliver L, Nakatsu C, Turco RF. (1999). Microbial biomass and activity in lead-contaminated soil. Appl Environ Microbiol 65: 2256-2259.

Konstantinidis KT, Isaacs N, Fett J, Simpson S, Long DT, Marsh TL. (2003). Microbial diversity and resistance to copper in metal-contaminated lake sediment. Microb Ecol 45: 191-202.

Kunito T, Nagaoka K, Tada N, Saeki K, Senoo K, Oyaizu H et al. (1997). Characterization of $\mathrm{Cu}$-resistant bacterial communities in Cu-contaminated soils. Soil Sci Plant Nutr 43: 709-717.

La Force MJ, Fendorf S, Li GC, Rosenzweig RF. (1999). Redistribution of trace elements from contaminated sediments of Lake Coeur d'Alene during oxygenation. J Environ Qual 28: 1195-1200. 
Lliros M, Casamayor EO, Borrego C. (2008). High archaeal richness in the water column of a freshwater sulfurous karstic lake along an interannual study. FEMS Microbiol Ecol 66: 331-342.

Ludwig W, Strunk O, Westram R, Richter L, Meier H, Yadhukumar et al. (2004). ARB: a software environment for sequence data. Nucleic Acids Res 32: 1363-1371.

MacGregor BJ, Moser DP, Alm EW, Nealson KH, Stahl DA. (1997). Crenarchaeota in Lake Michigan sediment. Appl Environ Microbiol 63: 1178-1181.

Mahapatra NR, Banerjee PC. (1996). Extreme tolerance to cadmium and high resistance to copper, nickel and zinc in different Acidiphilium strains. Lett Appl Microbiol 23: 393-397.

Moffett BF, Nicholson FA, Uwakwe NC, Chambers BJ, Harris JA, Hill TCJ. (2003). Zinc contamination decreases the bacterial diversity of agricultural soil. FEMS Microbiol Ecol 43: 13-19.

Mountfort DO, Asher RA. (1981). Role of sulfate reduction versus methanogenesis in terminal carbon flow in polluted inter-tidal sediment of Waimea Inlet, Nelson, New-Zealand. Appl Environ Microbiol 42: 252-258.

Odum EP. (1985). Trends expected in stressed ecosystems. Bioscience 35: 419-422.

Pedersen D, Sayler GS. (1981). Methanogenesis in freshwater sediments-inherent variability and effects of environmental contaminants. Can J Microbiol 27: 198-205.

Pouliot J, Galand PE, Lovejoy C, Vincent WF. (2009). Vertical structure of archaeal communities and the distribution of ammonia monooxygenase A gene variants in two meromictic High Arctic lakes. Environ Microbiol 11: 687-699.

Prusty BG, Sahu KC, Godgul G. (1994). Metal contamination due to mining and milling activities at the Zawar zinc mine, Rajasthan, India .1. Contamination of stream sediments. Chemical Geo 112: 275-291.

Pyatt FB, Gilmore G, Grattan JP, Hunt CO, McLaren S. (2000). An imperial legacy? An exploration of the environmental impact of ancient metal mining and smelting in southern Jordan. J Archaeol Sci 27: 771-778.

Raskin L, Amann RI, Poulsen LK, Rittmann BE, Stahl DA. (1995). Use of ribosomal RNA-based molecular probes for characterization of complex microbial communities in anaerobic biofilms. Water Sci Technol 31: 261-272.

Raskin L, Capman WC, Kane MD, Rittmann BE, Stahl DA. (1996). Critical evaluation of membrane supports for use in quantitative hybridizations. Appl Environ Microbiol 62: 300-303.

Robertson CE, Harris JK, Spear JR, Pace NR. (2005). Phylogenetic diversity and ecology of environmental Archaea. Curr Opin Microbiol 8: 638-642.

Sandaa RA, Enger O, Torsvik V. (1999a). Abundance and diversity of Archaea in heavy-metal-contaminated soils. Appl Environ Microbiol 65: 3293-3297.

Sandaa RA, Torsvik V, Enger O. (2001). Influence of long-term heavy-metal contamination on microbial communities in soil. Soil Biol Biochem 33: 287-295.

Sandaa RA, Torsvik V, Enger O, Daae FL, Castberg T, Hahn D. (1999b). Analysis of bacterial communities in heavy metal-contaminated soils at different levels of resolution. FEMS Microbiol Ecol 30: 237-251.

Schindler DW. (1990). Experimental perturbations of whole lakes as tests of hypotheses concerning ecosystem structure and function. Oikos 57: 25-41.

Shannon CE, Weaver W. (1949). The Mathematical Theory of Communication. University of Illinois Press: Urbana, Illinois.

Smit E, Leeflang P, Wernars K. (1997). Detection of shifts in microbial community structure and diversity in soil caused by copper contamination using amplified ribosomal DNA restriction analysis. FEMS Microbiol Ecol 23: 249-261.

Speir TW, Van Schaik AP, Percival HJ, Close ME, Pang LP. (2003). Heavy metals in soil, plants and groundwater following high-rate sewage sludge application to land. Water Air Soil Pollut 150: 319-358.

Spellerberg IF. (1991). Monitoring Ecological Change. Cambridge University Press: Cambridge.

Stein LY, Jones G, Alexander B, Elmund K, Wright-Jones C, Nealson KH. (2002). Intriguing microbial diversity associated with metal-rich particles from a freshwater reservoir. FEMS Microbiol Ecol 42: 431-440.

Utgikar VP, Chen BY, Chaudhary N, Tabak HH, Haines JR, Govind R. (2001). Acute toxicity of heavy metals to acetate-utilizing mixed cultures of sulfate-reducing bacteria: EC100 and EC50. Environ Toxicol Chem 20: 2662-2669.

Webb SM, Leppard GG, Gaillard JF. (2000). Zinc speciation in a contaminated aquatic environment: characterization of environmental particles by analytical electron microscopy. Environ Sci Technol 34: 1926-1933.

Winfrey MR, Zeikus JG. (1977). Effect of sulfate on carbon and electron flow during microbial methanogenesis in freshwater sediments. Appl Environ Microbiol 33: 275-281.

Supplementary Information accompanies the paper on The ISME Journal website (http://www.nature.com/ismej) 